\title{
AGRICULTURA FAMILIAR E AGROTÓXICO: DIALOGANDO COM A REALIDADE EM COMUNIDADES CAMPESINAS DE MIGUEL ALVES (PI) ${ }^{1}$
}

\section{Family agriculture and agrotoxic: dialogue with reality in peasant communities in Miguel Alves (PI)}

\author{
Antonio Carlos Rebelo de Paiva Filho ${ }^{2}$ \\ Sandra Regina de Sousa Cardoso ${ }^{3}$ \\ Juciane Vaz Rego ${ }^{4}$
}

\begin{abstract}
RESUMO: O presente trabalho tem como objetivo dialogar com as realidades vivenciadas por agricultores, sobre o uso de agrotóxicos, nas comunidades Malhada e Gameleira, na cidade de Miguel Alves (PI). Nesse sentido, buscou-se identificar os agrotóxicos utilizados e avaliar o grau de conhecimento dos agricultores sobre o uso de agrotóxicos. Este trabalho foi realizado na forma de pesquisa qualitativa-quantitativa, descritiva e exploratória. A pesquisa foi realizada com 16 (dezesseis) agricultores em duas comunidades, através da aplicação de questionário, enfocando o uso, o manejo, os tipos de agrotóxicos e o equipamento de proteção individual utilizado. O perfil dos sujeitos da pesquisa é caracterizado por agricultores do sexo feminino e masculino, com idade variando entre 20 a 83 anos, na comunidade Malhada; e 26 a 60 anos, na comunidade Gameleira, tendo, a maioria, cursado apenas o Ensino Fundamental. Observa-se que, os agricultores utilizam inseticidas e herbicidas, sem uma devida orientação de manejo e descarte incorreto das embalagens, embora tenham conhecimento sobre os riscos desses produtos ao ambiente e ao homem. Então, fica evidente a relevância deste estudo, visto que permitiu conhecer o cotidiano das comunidades campesinas pelos agricultores acerca da temática proposta.
\end{abstract}

Palavras-chave: Agricultura Familiar. Campesinos. Defensivo Agrícola. Educação do Campo.

\begin{abstract}
The present work aims to dialogue with the realities experienced by farmers, on the use of pesticides, in the communities Malhada and Gameleira, in the city of Miguel Alves (PI). In this sense, we sought to identify the pesticides used and evaluate the degree of knowledge of farmers on the use of pesticides. This work was carried out in the form of qualitative-quantitative, descriptive and exploratory research. The survey was carried out with 16 (sixteen) farmers in two communities, through the application of a questionnaire, focusing on the use, management, types of pesticides and the individual protection equipment used. The profile of the research subjects is characterized by female and male farmers, aged between 20 and 83 years, in the Malhada community; and 26 to 60 years old, in the Gameleira community, most of whom attended only elementary school. It is observed that, farmers use insecticides and herbicides, without proper
\end{abstract}

${ }^{1}$ Artigo obtido a partir do Trabalho de Conclusão de Curso (TCC) do Curso de Licenciatura e Educação do CampoLEDOC (UFPI).

${ }^{2}$ Graduado de Licenciatura em Educação do Campo/Ciências da Natureza pela Universidade Federal do Piauí (UFPI). E-mail: rebelofilho8519@,outlook.com.br

${ }^{3}$ Doutora em Agronomia (Proteção de Plantas) pela Universidade Estadual Paulista Júlio de Mesquita Filho (UNESP). Professora do Curso de Licenciatura em Educação do Campo (LEdoC) da Universidade Federal do Piauí (UFPI), Campus Ministro Petrônio Portella (CMPP), em Teresina (PI). E-mail: sandra.cardoso@,ufpi.edu.br

${ }^{4}$ Doutora em Biotecnologia (RENORBIO) pela Universidade Federal do Ceará (UFC). Professora do Curso de Licenciatura em Educação do Campo (LEdoC) da Universidade Federal do Piauí (UFPI), Campus Ministro Petrônio Portella (CMPP), em Teresina (PI).E-mail: juciane@,ufpi.edu.br 
guidance for handling and incorrect disposal of packaging, although they are aware of the risks of these products to the environment and to man. So, the relevance of this study is evident, since it allowed farmers to learn about the daily life of peasant communities about the proposed theme.

Keywords: Family Agriculture. Peasants. Agricultural Defensive. Rural Education.

\section{CONSIDERAÇÕES INICIAIS}

A agricultura é de suma importância para a humanidade, pois é o setor responsável pelo abastecimento de alimentos da sociedade e gerador de renda. As práticas agrícolas começaram a se desenvolver há cerca de dez mil anos pelo homem "pré-histórico", o que lhe permitiu, gradativamente, deixar de ser coletor e nômade (NORO; SEREIA, 2014).

Com o crescimento acelerado da população e, consequentemente, a necessidade de produzir mais alimentos, houve a indispensabilidade de intensificação da agricultura. Somente há pouco mais de meio século, que o uso intensivo de agrotóxicos vem sendo disseminado na agricultura para combater o ataque de pragas e doenças (LONDRES, 2011), mais precisamente, na década de 1950, nos Estados Unidos, através da denominada "Revolução Verde", que objetivou modernizar a agricultura e aumentar sua produtividade; no Brasil, chega na década de 1960 e ganha impulso com a implantação do Programa Nacional de Defensivos Agrícolas (PNDA) (LOPES; ALBUQUERQUE, 2018). Tal programa, estava vinculado à concessão de crédito agrícola, consequentemente, o Estado foi um grande responsável ao incentivo do uso de agrotóxicos no país (SIQUEIRA et al., 2013), sendo este, um dos pilares da "revolução verde".

O processo de modernização agrícola no Brasil se deu de forma acelerada e fragmentada, causando enorme variedade de situações: modificações de áreas que trabalhavam com a agropecuária tradicional, êxodo rural, periferização das pequenas e médias cidades, conflitos por posse da terra, expansão da fronteira agrícola e desmatamento excessivo (SOBRINHO et al., 2017). Percebe-se que grandes foram os impactos negativos da revolução verde para a agricultura, especialmente campesina, e para os recursos naturais. Infelizmente, ainda hoje esse é o modelo predominante no mundo.

Acerca dos agrotóxicos, lamentavelmente, não é uma realidade apenas da agricultura industrial, mas vem há tempos, também fazendo presença na agricultura familiar ${ }^{5}$. Realidade mais preocupante é o fato de que, muitos campesinos utilizam os agrotóxicos de forma indiscriminada

\footnotetext{
${ }^{5}$ Segundo Savoldi; Cunha (2010, p. 28-29): “o universo da agricultura familiar no Brasil é extremamente heterogêneo e inclui desde famílias muito pobres as quais detém, em caráter precário, um pedaço de terra que dificilmente pode servir de base para uma unidade de produção sustentável, até famílias com dotação de recursos, terra, capacitação, organização, conhecimento".
} 
e sem nenhum equipamento de proteção. Outro aspecto importante a se considerar é que com a aplicação desenfreada desses produtos contra as pragas e doenças, cada vez mais espécimes resistentes aos venenos estão sendo selecionadas. Aliado a isso, cabe salientar que tais pesticidas não atuam apenas sobre organismos considerados pragas, mas acabam por eliminar também, das áreas agrícolas, os inimigos naturais desses organismos (predadores e parasitoides). Diante o exposto, os produtores tornam-se cada vez mais dependentes dos agrotóxicos e de um número bem restrito destes.

Nesse contexto, dentre as atividades desenvolvidas no meio rural, o trabalho agrícola está sendo uma das ocupações mais preocupante na atualidade. E, cabe informar, que a agricultura familiar não é uma atividade importante apenas para o sustento das famílias campesinas, mas é de conhecimento que a maioria dos alimentos consumidos no Brasil é proveniente desse modelo de fazer agricultura, e embora tenha sido influenciado pela modernização agrícola, ainda cultiva técnicas e práticas tradicionais, proporcionando geração de emprego e renda no campo.

Dentre as diversas preocupações que causa o setor agrícola, neste estudo, iremos realçar o uso dos agrotóxicos. No Brasil, são regulamentados pela Lei no 7.802, de 11 de julho de 1989, seguida pelo Decreto n ${ }^{\circ} 4.074$, de 4 de janeiro de 2002, e são considerados:

Os produtos e os agentes de processos físicos, químicos ou biológicos, destinados ao uso
nos setores de produção, no armazenamento e beneficiamento de produtos agrícolas, nas
pastagens, na proteção de florestas, nativas ou implantadas, e de outros ecossistemas,
assim também de ambientes urbanos, hídricos e industriais, com intenção de preservar
flora e fauna da ação danosa de seres vivos considerados nocivos. (BRASIL,1989, Art. 2)

Os agrotóxicos podem acarretar uma série de consequências à saúde humana e ao meio ambiente. No homem, os agrotóxicos podem provocar a morte ou levar as intoxicações agudas (contato recente com o produto químico), como: fraqueza, cólicas, vômitos, espasmos musculares; e irritações crônicas (contato direto e prolongado com o produto) podem desencadear insuficiências renais, problemas neurológicos, paralisia, lesões hepáticas, renais, alergia, asma brônquica, alteração cromossômica, dermatites de contato e canceres (LONDRES, 2011; CARNEIRO et al., 2015).

Com relação ao meio ambiente, os agrotóxicos contaminam a flora, a água de lagos, riachos, lençol freático e solo, promovendo a morte de microorganismos que compõe a microbiota, e também, podem causar intoxicação ou levar a morte de animais importantes da fauna, causando desequilíbrio ambiental. Segundo Pereira; Costa; Lima (2019, p. 36), “o uso de agrotóxicos na agricultura aparece como um risco de ordem química que compromete todo o meio ambiente, 
assim como a cadeia alimentar dos seres vivos e alimentação humana, podendo levar a ocorrência de sérios impactos na saúde do indivíduo".

No entanto, os campesinos estão à mercê do uso de produtos tóxicos, sem saber a forma correta de utilizá-los, o que fazer com as embalagens, a dosagem correta dos produtos etc. Segundo Garcia; Bussacos; Fisher (2005), determinadas medidas podem reduzir o consumo de agrotóxico e, a consequente, redução às intoxicações, dentre elas: restrição da comercialização, legislação que restringe o uso dos agrotóxicos, uso controlado do agrotóxico com agente técnico responsável.

Além disso, o uso dos Equipamentos de Proteção Individual (EPI) contribui para a redução à exposição do trabalhador aos agrotóxicos e assim, aumenta a segurança durante o manuseio. São eles: máscara com filtro, touca árabe, óculos para produtos químicos, calça e jaleco impermeável, luvas de plástico, comprida, avental de plástico, botas de borracha (ANDEF, 2001). Entretanto, o agricultor durante a aplicação do agrotóxico não utiliza os EPI ou utiliza-os de forma inadequada, promovendo um elevado número de acidentes (CARNEIRO et al., 2015).

Embora muitos países estejam cada vez mais proibindo uso de muitos desses produtos químicos, o Brasil tem alargado ainda mais as possibilidades do seu uso. Segundo Brito (2016), entre os 50 venenos que mais usam, pelo menos 22 já são proibidos na União Europeia, na China ou no Canadá. Enquanto muitos países tendem a reduzir ou, até mesmo, eliminar o uso de produtos tóxicos nos seus sistemas de plantio, o Brasil segue na contramão, quando ainda insiste em usar esses produtos, para fins lucrativos, tanto da indústria que os produz, quanto de quem comercializa o plantio. De acordo com Terra; Pelaez (2008, p. 01), “o Brasil é um grande consumidor de agrotóxicos, sendo que em 2004 foi responsável por 13,5\% do faturamento da indústria mundial, terceiro maior índice em nível global, atrás apenas dos Estados Unidos e do Japão”.

Frente a questão do consumo de agrotóxico e os riscos que causam ao meio ambiente e ao homem, se faz necessário conhecer as realidades vivenciadas em comunidades rurais e, a partir disso, desencadear futuras intervenções sociais que promovam a sensibilização acerca das consequências do uso indiscriminado e inadequado.

Sendo assim, o presente trabalho tem como objetivo dialogar com as realidades vivenciadas por agricultores, sobre o uso de agrotóxicos, nas comunidades Malhada e Gameleira na cidade de Miguel Alves (PI). Nesse contexto, buscou-se identificar os agrotóxicos utilizados pelos agricultores e avaliar o grau de conhecimento dos mesmos sobre o uso de agrotóxicos.

As proposições metodológicas adotadas foram uma abordagem exploratória, descritiva e quali-quantitativa, por meio de pesquisa bibliográfica, aplicação de questionário e análise dos dados. 


\section{METODOLOGIA}

Esta pesquisa foi realizada nas comunidades Malhada e Gameleira, situadas, respectivamente, a 30 e $33 \mathrm{~km}$ da sede do município de Miguel Alves (PI). Este estudo se deu junto à agricultores dessas comunidades. Assim, os sujeitos da pesquisa foram 16 agricultores, sendo 6 da comunidade Gameleira e 10 da Malhada.

A pesquisa caracteriza-se como exploratória e descritiva, desenvolvida em área onde existe pouco conhecimento estruturado e explora-se a realidade a fim de que, posteriormente, seja feita pesquisa descritiva do objeto de estudo, as suas características e os problemas relacionados. Além disso, a abordagem deste estudo foi quali-quantitativa, tanto pelo uso de ferramentas quantitativas para tabulação dos dados, visando medir relações existentes entre variáveis, bem como, qualitativa que tem como enfoque o ambiente natural, como fonte direta dos dados com significância atribuída pelas pessoas às coisas e à vida (ALMEIDA, 2014).

A pesquisa foi constituída nas seguintes etapas, a saber:

(a) levantamento de pesquisas bibliográficas em bases onlines, leituras de artigos científicos e livros durante o desenvolvimento do tema proposto; (b) explicação para os sujeitos acerca do Termo de Consentimento Livre e Esclarecido (TCLE), para consentimento dos agricultores da comunidade; (c) na etapa seguinte, foi aplicado questionário com os agricultores, objetivando identificar os agrotóxicos utilizados pela comunidade e conhecer o grau de conhecimento sobre o modo de uso e riscos à saúde, o uso indiscriminado, manejo e destinos de embalagens.

\section{RESULTADOS E DISCUSSÃO}

O Brasil é o maior consumidor mundial de agrotóxicos, dado estimado pelo volume comercializado no país. A utilização dos agrotóxicos tem trazido sérias consequências, tanto para o meio ambiente, como para a saúde da população, especialmente os trabalhadores camponeses e suas famílias (CARNEIRO et al., 2015).

Acerca do tema, a pesquisa consistiu em um diálogo produtivo, conhecendo o cotidiano dos agricultores das comunidades campesinas, na sua prática da agricultura familiar, no que tange ao uso do agrotóxico, pois entende-se que eles precisam ser ouvidos, para que a Educação do Campo não apenas traga conteúdos prontos e acabados para dentro das comunidades, mas que trate das realidades e vivências dos envolvidos, fazendo do estudo algo mais interessante, construtivo e participativo. 


\subsection{Perfil dos agricultores e grau de conhecimento sobre o uso de agrotóxicos}

Verificou-se com a pesquisa, que o sexo dos agricultores da comunidade Gameleira tem proporção igualitária, feminino $(50 \%)$ e masculino (50\%). Na comunidade Malhada, a maioria é do sexo masculino (80\%) e feminino (20\%). Verifica-se um percentual expressivo das mulheres como agricultoras, sendo que ainda realizam outras atividades, como: atividades domésticas, a quebra do babaçu com participação na associação e produção de hortaliças. Nessa lógica, Schneider; Wedig (2019, p. 16) relatam:

As mulheres sempre desempenharam atividades fundamentais na agricultura camponesa, essencialmente relacionadas a manutenção da família e da propriedade rural. Há uma necessidade emergente de reconhecimento, valorização e visibilidade das atividades e papéis desempenhados pelas mulheres na agricultura camponesa.

A respeito da escolaridade dos agricultores da comunidade Gameleira, a maioria possui Ensino Fundamental (67\%) e Ensino Médio (33\%), diferentemente, da comunidade Malhada que tem 90\% de agricultores com Ensino Fundamental e 10\% não têm nenhuma escolaridade. A baixa escolaridade dos agricultores pode ser prejudicial no entendimento das informações na embalagem de produtos químicos, o que pode interferir na dosagem e preparo do agrotóxico (SANTANA et al., 2016; MOREIRA et al., 2002).

Segundo o Censo Agropecuário (2017), divulgado pelo IBGE, mostra que a situação no Brasil é alarmante, pois o estudo aponta um elevado número de analfabetos que aplicam agrotóxico no campo $(15,6 \%)$ e, destes, $89 \%$ declararam não ter recebido qualquer tipo de orientação técnica. Essas informações demonstram que existe uma relação da baixa escolaridade e a falta de orientação do campesino com o uso inadequado acentuado do produto químico.

Figura 1: Idade dos agricultores da comunidade Malhada e Gameleira, Miguel Alves (PI)

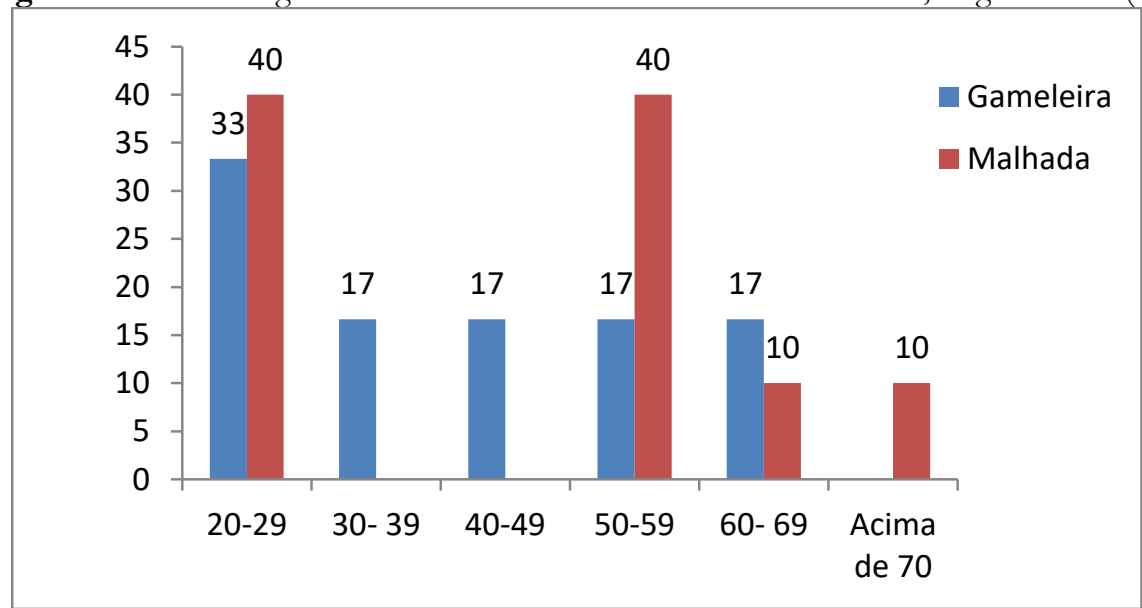

Fonte: Elaborada pelos autores (2018) 
A idade dos agricultores variou de 20 a 83 anos na comunidade Malhada; e 26 a 60 anos na comunidade Gameleira. Observa-se, na Figura 1 que os agricultores jovens ${ }^{6}$ representam uma parcela de 33\% na comunidade Gameleira, seguido de 50\% adultos e 17\% idosos ${ }^{7}$. Na comunidade Malhada, a representação encontra-se $40 \%$ jovens, $40 \%$ adultos e $20 \%$ idosos. Ressalta-se que, um fator que ainda interfere nesta distribuição, seja o êxodo rural nas comunidades, pois a maioria dos filhos dos trabalhadores rurais procuram as cidades para estudar e/ou trabalhar e assim, deixam o campo e migram para a cidade ou para outras regiões, em busca de trabalho e de melhores condições de vida. Ademais, foi verificado que são poucos os jovens que estão ligados diretamente no setor de produção do campo.

A Figura 2 informa sobre quando se tem início o uso de agrotóxico e sobre a adesão dos agricultores ao seu uso. Observa-se que comunidade Gameleira é a primeira a usar essa prática (2002), apresenta aumento no número de agricultores com uso de agrotóxico a partir de 2008, mantendo constante desde 2014. Enquanto isso, embora a comunidade Malhada só inicie anos depois, a utilização desses produtos, permanece demostrando crescente número de agricultores aderindo ao uso de agrotóxicos.

Figura 2: Tempo de uso dos agrotóxicos pelos agricultores da comunidade Gameleira e Malhada, Miguel Alves (PI)

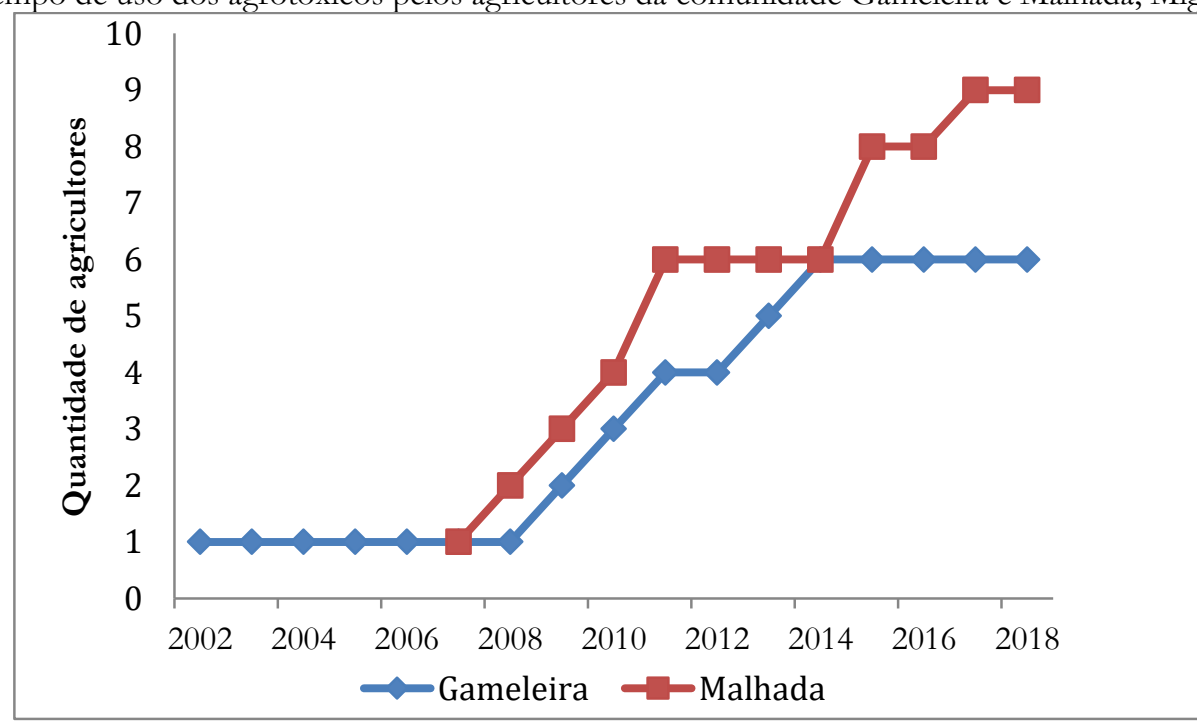

Fonte: Elaborada pelos autores (2018)

Esses dados evidenciam que, em ambas as comunidades, tem-se a presença de agrotóxico. A comunidade Gameleira tem um histórico de uso mais prolongado. O período que mais cresceu

\footnotetext{
${ }^{6}$ De acordo com o Estatuto da Juventude, Lei no 12.852 05/08/2013 (BRASIL, 2013).

${ }^{7}$ De acordo com o Estatuto do Idoso, Lei no 10.741 01/10/2003 (BRASIL, 2003).
} 
o número de agricultores com adesão ao uso dos agrotóxicos foi comum a ambas (2008 a 2014). A comunidade Malhada continua demonstrando crescente aumento no número de produtores que fazem uso desse método de controle de pragas e plantas daninhas e, desde 2014, todos os agricultores entrevistados da comunidade Gameleira já utilizam produtos químicos.

O uso indiscriminado de agrotóxicos pode ser explicado por serem de fácil acesso ao mercado, muito difundidos como uma melhor solução para a agricultura nos últimos tempos. Dessa forma, os trabalhadores rurais, na maioria das vezes, aplicam o produto sem noção do perigo que representa os agrotóxicos. Carneiro et al. (2015) corroboram nosso entendimento, quando aponta que os trabalhadores rurais são vulneráveis, tanto a facilidade de acesso, quanto ao incentivo do uso dos agrotóxicos, em contrapartida, não possuem seguridade social e a escolaridade mínima necessária para lidar com substâncias perigosas.

Analisando a Figura 3, nota-se que todos os agricultores da comunidade Gameleira afirmam perceber a presença de insetos considerados pragas, como: vaquinhas, lagarta, percevejo e formiga e, a maioria também aponta para o pulgão. Também foi alto o percentual de agricultores da comunidade Malhada que aponta para lagarta, percevejo e pulgão, enquanto que a maioria não tem percebido a presença de vaquinha e formiga em suas lavouras. Assim, verifica-se que é comum, em ambas as comunidades, a presença de lagarta, percevejo e pulgão. Cabe aqui, observar que a comunidade Gameleira possui período de tempo maior para o uso de agrotóxico (14 anos) e isso pode explicar os maiores percentuais encontrados, com exceção do pulgão.

Figura 3: Pragas que afetam as principais culturas (arroz, milho e feijão) dos agricultores da Comunidade Gameleira e Malhada, Miguel Alves (PI)

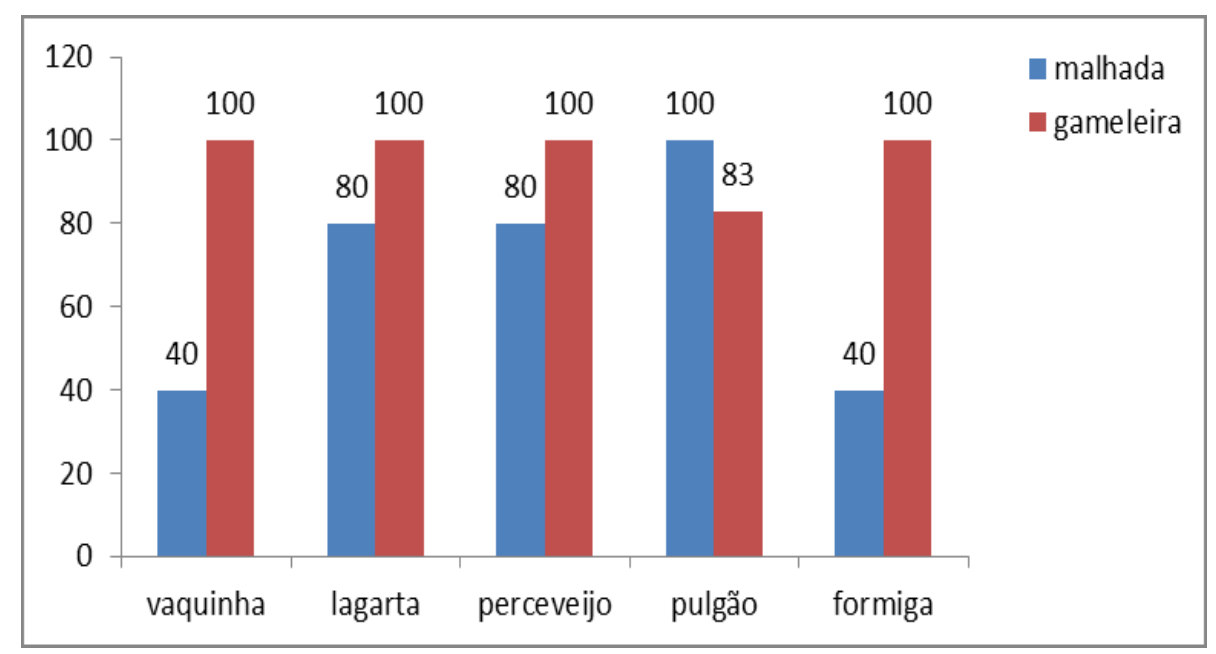

Fonte: Elaborada pelos autores (2018)

Dados do Departamento de Meio Ambiente do governo dos EUA (EPA, na sigla em inglês) indicam que na década de 1970 os agricultores do país usavam 25 mil toneladas de 
agrotóxicos e perdiam 7\% da lavoura antes da colheita. No final da década de 1990, usavam 12 vezes mais agrotóxicos e perdiam o dobro do que anteriormente (VAZ, 2006). Isso se dá porque as pragas agrícolas possuem a capacidade de selecionar populações com resistência aos produtos químicos, como agrotóxicos aplicados: com o tempo, esses venenos vão perdendo eficácia e levando os agricultores a aumentar as doses aplicadas e/ou recorrer a novos produtos. A indústria está sempre trabalhando no desenvolvimento de novas moléculas, que são anunciadas como "a solução" para o controle das pragas, doenças ou plantas invasoras, que, com o tempo, serão substituídas por outras novas, e assim, infinitamente. Trata-se de um círculo vicioso, do qual o agricultor não consegue se libertar.

Outro elemento chave nesse processo é o desequilíbrio ambiental, provocado por esses sistemas que leva também ao surgimento de novas pragas. Em outras palavras, insetos ou plantas que antes não provocavam danos às lavouras, passam a se comportar como invasores e atacar as plantações (VAZ, 2006). Os insetos vivem no seu habitat natural. No entanto, o homem desmata a natureza para produzir alimentos, e é esse fator que faz com que os insetos afetem as culturas agrícolas, porém, na cadeia produtiva nem todos os insetos são considerados nocivos, no entanto, quando se aplica veneno no meio ambiente, muitos outros insetos não prejudiciais, também são eliminados da cultura (MEDEIROS, 2010).

$\mathrm{Na}$ agricultura familiar foi introduzido o uso de agrotóxicos como se fosse uma solução para melhor produzir alimentos para a população, as mídias colocam a ideia de que os produtos são benéficos e essenciais ao cultivo agrícola. Assim, além da baixa escolaridade, citada como fator que pode influenciar nas leituras dos rótulos e favorecer o uso do agrotóxico de forma inadequada, também deixam se envolver pelas propagandas e não se atentam em consultar um profissional da área para prestar as orientações cabíveis.

No Quadro 1 tem-se os inseticidas mais utilizados pelos agricultores nas duas comunidades em questão, a classificação e toxicidade destes. Observa-se que agricultores usam produtos que variam de altíssima a baixa toxicidade. Sobre a numeração de cada produto, cabe saber que I e II corresponde a extrema toxicidade (faixa vermelha) e IV menor toxicidade (faixa verde), sendo a numeração III toxicidade intermediária/mediana (faixa azul). São classificados como sistêmico, os inseticidas que agem no inseto, aqueles capazes de serem translocados pela planta, ou seja, aplicado sobre folhas, troncos, ramos, raízes e sementes é capaz de ser absorvido e circular com a seiva para todas as partes da planta. O inseticida se dá pelo contato com o corpo do inseto, penetrando na epicutícula e sendo conduzido através do tegumento, onde irá atuar sobre as terminações nervosas. 
Quadro 1: Inseticidas mais utilizados pelos agricultores entrevistados

\begin{tabular}{|c|c|c|c|}
\hline INSETICIDA & CLASSE & TOXIDADE & COR DA FAIXA \\
\hline Atabron & $\begin{array}{c}\text { Fisiológico inibidor da } \\
\text { síntese de quitina }\end{array}$ & I & Vermelho \\
\hline Lannate & Contato/sistêmico & II & Vermelho \\
\hline Engeo pleno & Sistêmico & III & Azul \\
\hline Actara & Sistêmico & III & Verde \\
\hline Evidence & Sistêmico & IV & - \\
\hline Barrage & Contato & Baixa & \\
\hline \multicolumn{2}{|c|}{ Fonte: Elaborado pelos autores (2018) }
\end{tabular}

Verifica-se que entre os compostos químicos mais utilizados pelos agricultores da comunidade Gameleira, são: Engeo pleno (33\%), Actara (33\%) e Evidence (17\%) (Figura 4A), onde possuem níveis de toxicidade III e IV, respectivamente médio e baixa toxicidade. Na comunidade Malhada Evidence (25\%), Actara (25\%), Lannate (17\%) (Figura 4B). Os produtos químicos de média a alta toxidade têm a capacidade de acarretar danos mais graves ao meio ambiente e a saúde do agricultor.

Actara é o inseticida que mais se destaca em ambas comunidades, é sistêmico e apresenta toxicidade intermediária. Em seguida, Engeo pleno para a comunidade Malhada (sistêmico e toxidade intermediária) e Evidence para comunidade Gameleira (sistêmico e baixíssima toxicidade).

Figura 4: Agrotóxicos (Inseticidas) utilizados por agricultores da Comunidade Gameleira (A) e Malhada (B), Miguel Alves (PI)

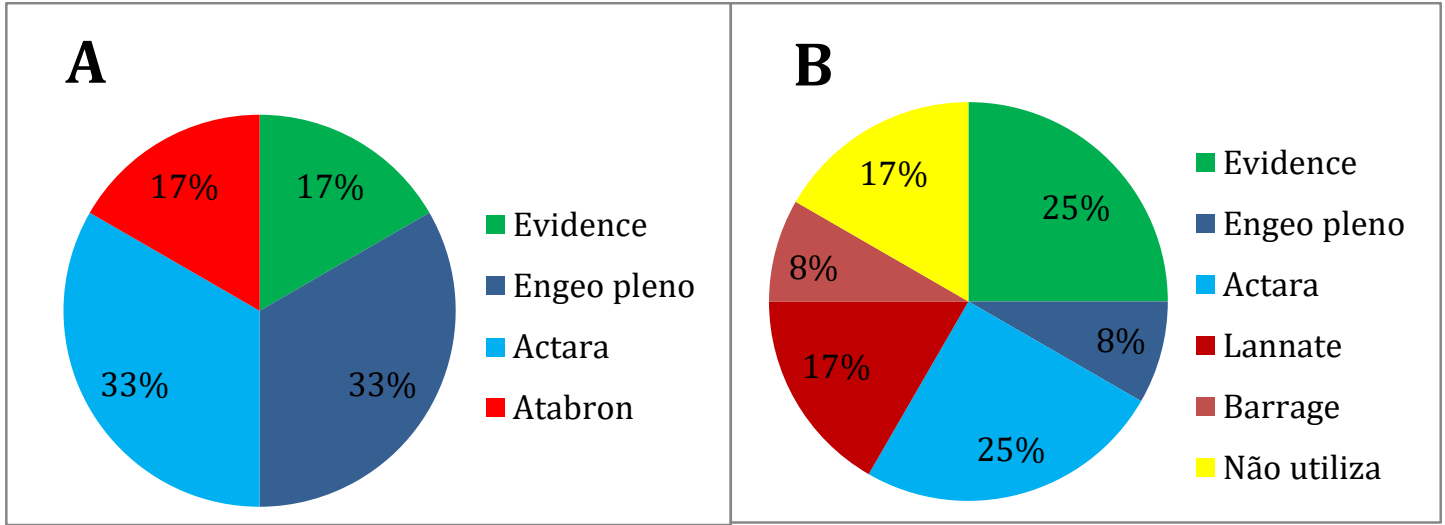

Fonte: Elaborada pelos autores (2018)

O uso de agrotóxicos foi estimulado sem a preocupação prévia de orientar os agricultores sobre o risco para a sua saúde, meio ambiente e para o consumidor, de forma a criar, entre os agricultores, um falso conceito que os produtos aplicados são praticamente inofensivos para o meio ambiente e a saúde do ser humano (MATA; FERREIRA, 2013).

O Quadro 2 mostra os herbicidas mais utilizados pelas comunidades Gameleira e Malhada, em Miguel Alves (PI), com seus graus de toxidade. Na comunidade Gameleira os 
produtos herbicidas mais utilizados são o 2,4-D (40\%), Randaup (30\%), Gramoxone (20\%) e Tordon $(10 \%)$ com níveis de toxidade variando entre I e II. Os agricultores da comunidade Malhada utilizam mais Gramoxone (36\%) 2,4D (29\%), Roundup (21\%) e Não usam (14\%).

Quadro 2: Herbicidas mais utilizados pelos agricultores entrevistados

\begin{tabular}{|c|c|c|c|}
\hline HERBICIDA & CLASSE & TOXIDADE & COR DA FAIXA \\
\hline Roundup & Sistemico/Contato & II & Vermelho/Amarelo \\
\hline Gramoxine & $\begin{array}{c}\text { Não seletivo/Não } \\
\text { sistêmico }\end{array}$ & I & Vermelho \\
\hline $2,4-D$ & $\begin{array}{c}\text { Sistêmico, Seletivo, Pós- } \\
\text { emergência }\end{array}$ & I & Vermelho \\
\hline Tordon & Sistêmico, Seletivo & I & Vermo \\
\hline
\end{tabular}

Fonte: Elaborado pelos autores (2018)

Na classificação, os herbicidas de contato atuam próximo ou no local onde são absorvidos nas plantas. O herbicida sistêmico é aquele que se movimenta, se transloca no interior da planta, pelo xilema ou floema, ou por ambos.

Como demonstrado no Quadro 2, um dos herbicidas mais utilizados nas duas comunidades (Gameleira e Malhada), é o 2,4-D (2,4-diclorofenoxiacético), o qual estava em análise na Anvisa desde 2006, e, em junho de 2016, a agência manteve parecer favorável à liberação do agrotóxico, apesar dos riscos apresentados à saúde. A Organização Mundial da Saúde (OMS) diz que esse tipo de agrotóxico afeta o sistema reprodutivo, o cérebro e é apontado como potencialmente cancerígeno (REDE BRASIL ATUAL, 2016).

Os agrotóxicos podem acarretar problemas de saúde do trabalhador rural, por isso, destaca-se a importância de implementações das ações em educação em saúde. Nessa compreensão, Preza; Augusto (2012, p. 89) enfatizam:

O Uso indiscriminado de agrotóxico em um contexto de vulnerabilidades sociais e institucionais compromete a saúde ambiental e do trabalhador, apontando para a necessidade de ações que levam à promoção e proteção à saúde do trabalhador rural, bem como na prevenção nas situações de risco ambiental.

Destaca-se na Figura 5, que os agricultores utilizam agrotóxicos em suas lavouras, mesmo sabendo que é prejudicial aos seres vivos, em geral, inclusive ao homem, a contaminação da água e solo. No entanto, parecem não ter noção do risco real da gravidade para sua própria saúde, tendo em vista, que o agrotóxico tem o poder acumulativo de resíduos.

Figura 5: Conhecimento da população sobre a contaminação de agrotóxicos das comunidades Gameleira e Malhada, Miguel Alves (PI) 


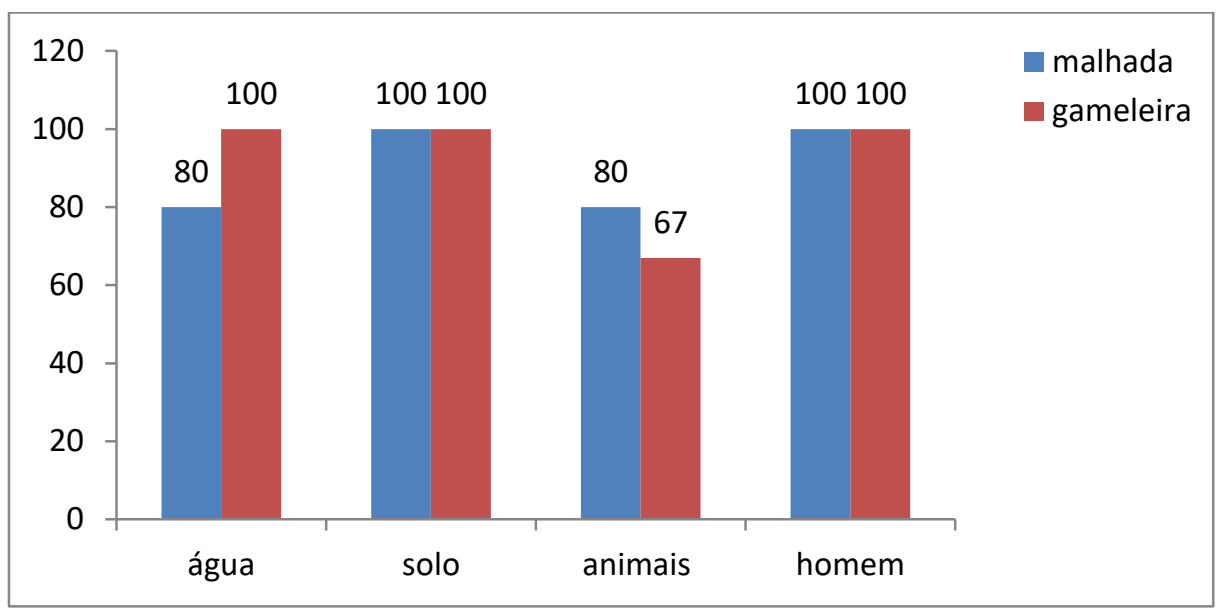

Fonte: Elaborada pelos autores (2018)

Assim, alguns agricultores sabem da gravidade, porém, insistem em manter o uso de agrotóxicos nas plantações para controle de insetos pragas e plantas consideradas daninhas às culturas. Contudo, existem alternativas ao cultivo "modernizado", como as práticas agroecológicas que fazem uso, dentre outros, de controle de insetos com produtos naturais e a cabina para controlar vegetação indesejável. É preciso repensar o modo de fazer agricultura, buscando práticas mais ecológicas e sustentáveis de produção, que minimizem os danos à saúde humana, conserve a biodiversidade e reduza os danos aos recursos naturais água, solo e ar.

De fato, a Agroecologia tem sido uma alternativa visada para minimizar os problemas causados pela agricultura proveniente da "Revolução Verde", configurando-se hoje, tema central e princípio da agricultura sustentável (SANTOS, 2018). Altieri (2004) defende que a Agroecologia fornece os princípios ecológicos básicos de como lidar com os recursos naturais nos agroecossistemas, para que sejam ambientalmente corretos, socialmente justos e economicamente viáveis.

Durante a pesquisa, também foi evidenciado que os agricultores não apresentam preocupação com o uso de EPI, pois não fazem uso durante a aplicação dos produtos químicos na agricultura. Embora os EPI não sejam eficientes para proteger, efetivamente, os trabalhadores do desenvolvimento de intoxicações crônicas, deixar de utilizá-los ou usar de forma inadequada, contribui para o elevado número de acidentes com agrotóxicos. Justificam que os EPI não são utilizados, pois não são disponibilizados pelos patrões, mas também, pelo desconforto e a incerteza quanto a sua eficácia (SCHMIDT; GODINHO, 2006; CASTRO; CONFALONIERI, 2005).

Para agravar a situação, a Figura 6 revela que a maioria dos agricultores admite preparar a solução do agrotóxico fazendo superdosagem na comunidade Gameleira (67\%) e Malhada (50\%). Acredita-se que os campesinos não tenham a informação e auxílio técnico para o preparo das soluções e entendem que quanto mais produto químico, melhor a ação do composto. Entretanto, 
a superdosagem ocasiona risco de saúde ao próprio agricultor que manipula o agrotóxico, contaminação ao meio ambiente e para quem consome os alimentos com resíduos (GUARDA et al., 2016).

Figura 6: A dosagem de uso do agrotóxico pelos agricultores da Comunidade Gameleira e Malhada, Miguel Alves (PI)

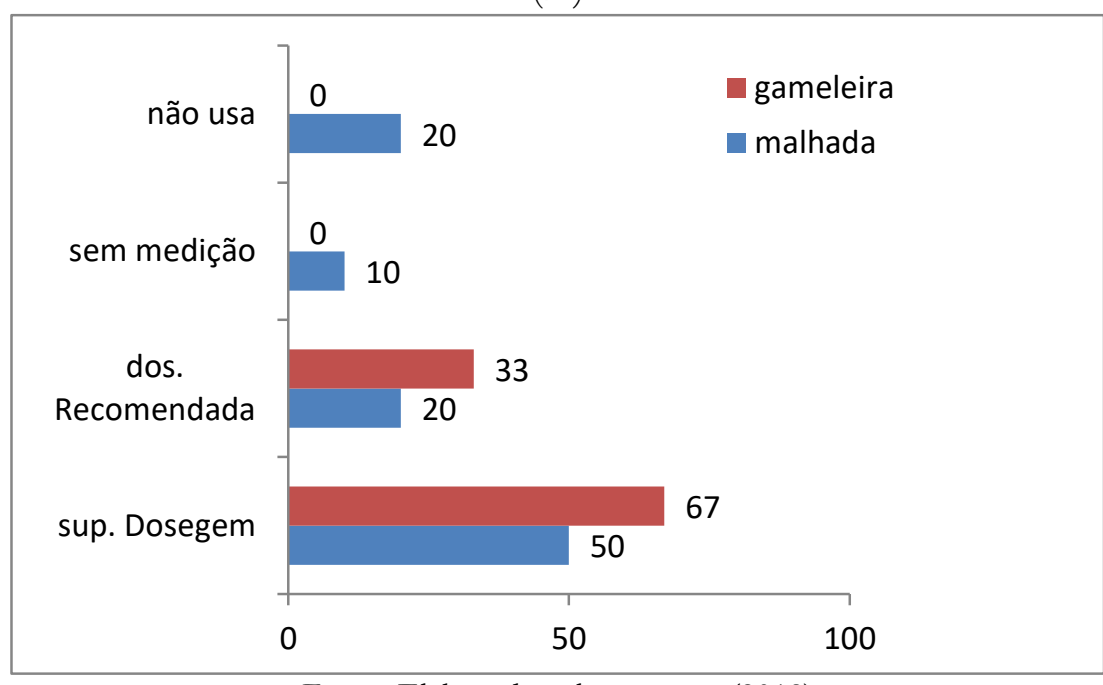

Fonte: Elaborada pelos autores (2018)

Com relação às embalagens dos agrotóxicos, a maioria dos agricultores, sujeitos da pesquisa, afirma fazer descarte no lixo ou a queima das embalagens em ambas as comunidades, Gameleira (100\%) e Malhada (80\%). O descarte ou a lavagem inadequada das embalagens desses produtos, também favorecem para a contaminação do homem e do ambiente (ALMUSSA; SCHMIDT, 2009).

A forma adequada de destino das embalagens, segundo a legislação, a Lei no 9.974, de 6 de junho de 2000 é:

\begin{abstract}
Os usuários de agrotóxicos, seus componentes e afins deverão efetuar a devolução das embalagens vazias dos produtos aos estabelecimentos comerciais em que foram adquiridos, de acordo com as instruções previstas nas respectivas bulas, no prazo de até um ano, contado da data de compra, ou prazo superior, se autorizado pelo órgão registrante, podendo a devolução ser intermediada por postos ou centros de recolhimento, desde que autorizados e fiscalizados pelo órgão competente. (BRASIL, 2000, Art. 1)
\end{abstract}

A lei federal orienta que as embalagens vazias devem ser devolvidas ao estabelecimento comercial, no entanto, sugere-se que os agricultores desconhecem essa medida, o que torna esta temática importante a ser trabalhada nas comunidades campesinas, visando que processos educativos sejam implementados. 


\section{CONSIDERAÇÕES FINAIS}

Esta pesquisa permitiu conhecer os principais agrotóxicos utilizados nas comunidades Gameleira e Malhada, Miguel Alves (PI): os herbicidas (Gramoxine, Roundup, 2,4 - D, Tordon) e inseticidas (Engeo pleno, Evidencia, Barrage, Actara, Lannate e Atabron). Possibilitou também, entender que os agricultores possuem conhecimento sobre o risco do agrotóxico à saúde, ao solo, aos animais e ao homem. Contudo, utilizam em superdosagem, sem o uso do EPI e fazem o descarte incorreto das embalagens, o que pode gerar risco a saúde do trabalhador e ao meio ambiente.

No município de Miguel Alves (PI) predomina a agricultura familiar, porém, nota-se um aumento considerável e gradual no incremento de agroquímicos nas lavouras dos agricultores familiares e, da maneira como o fazem, sem proteção e em superdosagem, acabam ficando expostos à contaminação por agrotóxicos, por anos seguidos.

Assim, é notável a importância e urgência de trabalhar a temática com agricultores em comunidades campesinas, para que alimentos sejam produzidos de forma sadia para o agricultor, o consumidor e ao ambiente. Além disso, é preciso levar a essas comunidades, alternativas de cultivo mais ecológicas e sustentáveis, que levem em conta a saúde de todos os envolvidos e o respeito ao meio ambiente. E mais além ainda, é preciso que o agricultor repense a forma de fazer agricultura, buscando nas práticas tradicionais, a inspiração e o resgate necessário desse conhecimento responsável pela produção de alimentos por tantos anos. Que façam adesão ao uso de tecnologias modernas, desde que não comprometam severamente a sanidade do meio, da biodiversidade e do homem

É necessário programas de educação e políticas públicas efetivas, que atuem nas comunidades campesinas, contribuindo com a redução do uso de agrotóxico, por meio de orientação educativa e técnica especializada sobre o uso e manejo adequado dos agrotóxicos e/ou o incentivo de culturas agroecológicas ou orgânicas para agricultura familiar.

\section{REFERÊNCIAS}

ALMEIDA, M. de S. Elaboração de projeto, TCC, dissertação e tese: uma abordagem prática e objetiva. 2. ed. São Paulo: Atlas, 2014.

ALMUSSA, A.; SCHMIDT, M. L. G. O contato com agrotóxicos e os possíveis agravos à saúde de trabalhadores rurais. Revista de Psicologia da UNESP, [S.1.], v. 8, n. 2, p.184-188, 2009.

ASSOCIAÇÃO NACIONAL EM DEFESA VEGETAL (ANDEF). Manual de boas práticas no uso dos EPI. 2001. Disponível em: < https://www.fmcagricola.com.br/images $\angle$ manuais/ANDEF MANUAL BOAS PRATICAS NO USO DE EPIs web.pdf $>$. Acesso em: 10 dez 2018. 
ALTIERI, M. Agroecologia: a dinâmica produtiva da agricultura sustentável. 5. ed. Porto Alegre Editora UFRGS, 2004.

BRASIL. Lei n. 7.802, de 12 de julho de 1989. (Lei Federal dos Agrotóxicos). Brasília, Diário Oficial da União, 12 jul. 1989. Disponível em: < http://www.planalto.gov.br/ccivil 03/leis/L7802.htm >. Acesso em: 14 ago. 2018.

BRASIL. Lei n. 9.974, de 6 de junho de 2000. Altera a Lei no 7.802, de 11 de julho de 1989, Brasília, Diário Oficial da União, 6 de jun. 2000. Disponível em: < http://www.planalto.gov.br/ccivil 03/LEIS/L9974.htm >. Acesso em: 14 ago. 2018.

BRASIL. Decreto no 4.074, de 4 de janeiro de 2002. Regulamenta a Lei $n^{\circ} 7.802$, de 11 de julho de 1989, que dispõe sobre a pesquisa, a experimentação, a produção, a embalagem e rotulagem, o transporte, o armazenamento, a comercialização, a propaganda comercial, a utilização, a importação, a exportação, o destino final dos resíduos e embalagens, o registro, a classificação, o controle, a inspeção e a fiscalização de agrotóxicos, seus componentes e afins, e dá outras providências. Diário Oficial da União, Edição nº 5, Seção 1, Brasília, DF, 8 jan. 2002. Disponível em: < https://www.gov.br/agricultura/pt-br/assuntos/insumosagropecuarios/insumos-agricolas/agrotoxicos/legislacao/arquivos-de-legislacao/decreto-40742002-decreto-dos-agrotoxicos/view >. Acesso em: 14 ago. 2018.

BRASIL. Estatuto do Idoso. Lei $n^{\circ} 10.741$, de $1^{\circ}$ de outubro de 2003. Dispõe sobre o Estatuto do Idoso e dá outras providências. Art. $1^{\circ}$ É instituído o Estatuto do Idoso, destinado a regular os direitos assegurados às pessoas com idade igual ou superior a 60 (sessenta) anos. Brasília: Senado Federal, 2003. Disponível em: < https://www2.senado.leg.br/bdsf/bitstream/handle/id/70326/672768.pdf?sequence $=2>$. Acesso em: 14 ago. 2018.

BRASIL. Lei no 12.852, de 5 de agosto de 2013. Institui o Estatuto da Juventude e dispõe sobre os direitos dos jovens, os princípios e diretrizes das políticas públicas de juventude e o Sistema Nacional de Juventude - SINAJUVE. Brasília, Diário Oficial da União, 6 de ago. 2013. Disponível em: < http://prattein.com.br/home/images/stories/Juventude/Estatuto da Juventude.pdf $>$. Acesso em: 14 ago. 2018.

BRITO, Gisele. Empresas pedem registro para produção de agrotóxicos danosos à saúde. Brasil de Fato, 13 jul. 2016. Disponível em: < https://www.brasildefato.com.br/2016/07/13/empresas-pedem-registro-para-producao-deagrotoxicosdanosos- a-saude/ > Acesso em: 10 ago. 2018.

CARNEIRO, Fernando Ferreira et al. (Org.) Dossiê ABRASCO: um alerta sobre os impactos dos agrotóxicos na saúde. Parte 1 - Agrotóxicos, Segurança Alimentar e Nutricional e Saúde. Rio de Janeiro: EPSJV; São Paulo: Expressão Popular, 2015. Disponível em: < http://aao.org.br/aao/pdfs/publicacoes/Dossie Abrasco 01.pdf > Acesso em: 15 out. 2018.

CASTRO, J. S. M.; CONFALONIERI, U. Uso de agrotóxicos no Município de Cachoeiras de Macacu (RJ). Ciência e Saúde Coletiva, Rio de Janeiro, v. 10, n. 2, p. 473-482, 2005. 
GARCIA, E. G.; BUSSACOS, M. A.; FISHER, F. M. Impacto da legislação no registro de agrotóxicos de maior toxicidade no Brasil. Revista de Saúde Pública, São Paulo, v. 39, n. 5, p. 832-839, 2005.

GUARDA, Patricia Martins et al. Panorama da utilização de agroquímicos em cultura de abacaxi no estado do Tocantins e possíveis problemas de contaminação. Revista Desafios, Tocantins, vol. 3, nº especial, p. 70-79, 2016.

INSTITUTO BRASILEIRO DE GEOGRAFIA E ESTATÍSTICA (IBGE). Censo agropecuário. Rio de Janeiro, v. 8, p. 01-105, 2017.

LONDRES, F. Agrotóxicos no Brasil: um guia para ação em defesa da vida. Rio de Janeiro: ASPTA - Assessoria e Serviços a Projetos em Agricultura Alternativa, 2011.

LOPES, C. V. A.; ALBUQUERQUE, G. S. C. de. Agrotóxicos e seus impactos na saúde humana e ambiental: uma revisão sistemática. Saúde em Debate, Rio de Janeiro, vol. 42, n. 117, p. 518$534,2018$.

MATA, João Siqueira da; FERREIRA, Rafael Lopes. Agrotóxico no Brasil: uso e impactos ao Meio Ambiente e a Saúde Pública. Ecodebate, 02 ago. 2013. Disponível em:

< https://www.ecodebate.com.br/2013/08/02/agrotoxico-no-brasil-uso-e-impactos-ao-meioambiente-e-asaude-publica-por-joao-siqueira-da-mata-e-rafael-lopes-ferreira/>. Acesso em: 14 out. 2018.

MEDEIROS, M. A de. Princípios e práticas ecológicas para manejo de insetos-praga na agricultura. Brasília: EMATER-DF, 2010.

MOREIRA, J. C. et al. Avaliação integrada do impacto do uso de agrotóxicos sobre a saúde humana em uma comunidade agrícola de Nova Friburgo, RJ. Ciência \& Saúde Coletiva, Rio de Janeiro, vol. 7, n. 2, p. 299-311, 2002.

NORO, V.; SEREIA, D. A. Trabalhando com projetos e problemáticas na formação de alunos reflexivos: o uso de agrotóxicos e seus impactos. In: O professor PDE e os desafios da escola pública paranaense: produção didático-pedagógica, 2010. Secretaria de Estado da Educação. Superintendência da Educação. Programa de Desenvolvimento Educacional. Curitiba: SEED-PR, 2014.

PEREIRA, Reobbe Aguiar; COSTA, Cristina Maciel Lima; LIMA, Eliana Maciel. O impacto dos agrotóxicos sobre a saúde humana e o meio ambiente. Revista Extensão, Bahia, v. 3, n. 1, p. 29 37, 2019.

PREZA, Débora de Lucca Chaves; AUGUSTO, Lia Giraldo da Silva. Vulnerabilidades de trabalhadores rurais frente ao uso de agrotóxicos na produção de hortaliças em região do Nordeste do Brasil. Revista Brasileira de Saúde Ocupacional, São Paulo, vol. 37, n. 125, p. 89-98, jan./jun., 2012.

REDE BRASIL ATUAL. Idec quer banir agrotóxico com componentes do agente laranja. 22 jun. 2016. Disponível em: < http://www.redebrasilatual.com.br/saude/2016/06/idec-querbanir-agrotoxico-com-componentes-doagente- laranja-417.html >. Acesso em: 15 out. 2018. 
SAVOLDI, Andréia; CUNHA, Luiz Alexandre. Uma abordagem sobre a agricultura familiar, PRONAF e a modernização da agricultura no Sudoeste do Paraná na década de 1970. Revista Geografar, Curitiba, v. 5, n. 1, p. 25-45, jan./jun., 2010. Disponível em: < https://revistas.ufpr.br/geografar/article/download/17780/11607 >. Acesso em: 16 out. 2018.

SANTANA, C. M. et al. Exposição ocupacional de trabalhadores rurais a agrotóxicos. Cadernos Saúde Coletiva, Rio de Janeiro, vol. 24, n. 3, p. 301-307, 2016.

SANTOS, Raimundo Nonato de Melo. Agrotóxicos e Agroecologia no Ensino de Ciências: pesquisa na Escola Família de Miguel Alves, PI. 2018. 33 f. Monografia (Licenciatura em Educação do Campo - Ciências da Natureza) - Centro de Ciências da Educação. Universidade Federal do Piauí, Teresina, 2018.

SIQUEIRA, Danielle Ferreira de et al. Análise da exposição de trabalhadores rurais a agrotóxicos. Revista Brasileira em Promoção da Saúde, Fortaleza, vol. 26, n. 2, p. 182-191, 2013.

SCHNEIDER, C. O.; WEDIG, J. C. Campesinato: caraterísticas e transformações decorrentes da modernização da agricultura. In: IX Seminário Internacional sobre Desenvolvimento Regional: Processos, Políticas e Transformações Territoriais. Anais... Santa Cruz do Sul (RS), set., 2019. p. 01-18.

SOBRINHO, F. L. A. et al. (Orgs). Agricultura contemporânea no Brasil: ruralidades, tecnificação e paisagens. Brasília: Universidade de Brasília; Departamento de Geografia, 2017.

SCHMIDT, M. L. G.; GODINHO, P. H. Um breve estudo acerca do cotidiano do trabalho de produtores rurais: intoxicações por agrotóxicos e subnotificação. Revista Brasileira de Saúde Ocupacional, São Paulo, v. 31, n. 113, p. 27-40, jun., 2006.

TERRA, F. H. B; PELAEZ, V. M. A evolução da indústria de agrotóxicos no Brasil de $2001 \mathrm{a}$ 2007: a expansão da agricultura e as modificações na lei de agrotóxicos. In: XLVI Congresso da Sociedade Brasileira de Economia, Administração e Sociologia Rural, Anais... Rio Branco, jul., 2008.

VAZ, P. A. B. Direito Ambiental e os agrotóxicos: responsabilidade civil, penal e administrativa. Porto Alegre: Livraria do Advogado Ed., 2006. 